\title{
A Quasi One-dimensional Simulation of a 4 Stroke Spark Ignition Hydrogen Fuelled Engine
}

\author{
Yusaf, T.F., M.Z. Yusoff, I. Hussein and S.H. Fong \\ Department of Mechanical Engineering, College of Engineering, University Tenaga National \\ Km 7, Jalan Kajang-Puchong, 43009, Kajang, Selangor Malaysia
}

\begin{abstract}
Active research and development of hydrogen-fuelled engine had been done for a few decades since hydrogen serves as a potential of infinite fuel supply. This paper discussed analytically and provides data on effects of compression ratio, equivalence ratio and spark timing of a hydrogenfuelled engine as a guideline for the engine design. The change in the thermodynamic properties of the fuel was considered through the engine cycle. A modified version of Olikara and Borman method was presented to track the mole fraction of the equilibrium state of combustion products for hydrogen fuel. The equilibrium values of each species were used to predict the $\mathrm{NO}_{\mathrm{x}}$ formation, which is the main concern of study for hydrogen-fuelled engine.
\end{abstract}

Key words: Hydrogen, knock, $\mathrm{NO}_{\mathrm{x}}$, spark ignition and Olikara and Borman

\section{INTRODUCTION}

The rapidly increasing worldwide demand for the energy and the progressive depletion of fossil fuels has led to an intensive search for alternative fuels which can be produced on a renewable basis. Hydrogen becomes the right candidate due to its desirable characteristics such as clean burning, no unburned hydrocarbons, particulate matter, sulphur dioxide, smoke and etc. Hydrogen has a wide range of flammability, low ignition energy, small quenching distance, high autoignition temperature, flame speed and diffusivity, which are suitable characteristics of as an engine fuel. However, these will bring the adverse effect in certain circumstances. The low ignition energy enables the conventional ignition system to be effective with a very low energy spark but at the same time it makes the system susceptible to surface ignition. Surface ignition is a highly undesirable combustion phenomenon because it precipitates flashback, pre ignition (knock) and rapid rate of pressure rise. The small quenching distance of hydrogen, makes the flame in a hydrogen-air mixture escapes more readily to the intake valve. Therefore, the fuel properties directly affect the engine design.

Descriptions of the mathematical model: The mathematical model was applicable in any types of fuels provided the fuel induction technique was used or in other words the carburetion system. The simulation is to predict the hydrogen gas inducted through the air inlet and serves as an alternative fuel to combust with fresh air. From the first law of thermodynamics, the open system can be defined as:

$$
\Delta U=Q-W
$$

where the change of internal energy of a system is equal to the difference between the heat and work generated by the system. Taking the derivative of equation (1) yields:

$m \frac{d u}{d \theta}+u \frac{d m}{d \theta}=\frac{d Q}{d \theta}-P \frac{d V}{d \theta}-\frac{\dot{m}_{1} h_{1}}{\omega}$

where, $m_{1}$ is mass flow rate, $h_{1}$ is the enthalpy of the blow by the masses, $u$ is internal energy, $Q$ is heat transfer, $p$ is pressure, $V$ is volume, $\theta$ is crank angle and $\omega$ is the engine speed

Thermodynamic properties: Equation (2) shows that the thermodynamic properties change with respect to the crank angle, but at the same time the properties are also functions of temperature and pressure as well.

The subscript represent the burned and unburned gas zone whereby $\mathrm{x}$ is the fraction between them. The entropy is only considered in the unburned gas zone since the unburned gas was treated as an open system losing mass due to leakage and during combustion process.

\begin{tabular}{lll} 
Table 1: Thermodynamics properties expression ${ }^{[1]}$ \\
\hline Specific internal energy & $u=u(T, P) \quad u=\frac{U}{m}=x u_{b}+(1-x) u_{u}$ \\
Specific volume & $v=v(T, P) \quad v=\frac{U}{m}=x v_{b}+(1-x) v_{u}$ \\
Specific entropy & $\begin{array}{l}s_{u}=s\left(T_{u}, P\right) \\
\text { Specific enthalpy } \\
h=h(T, P)\end{array}$
\end{tabular}

Corresponding Author: Yusaf T F, Department of Mechanical Engineering, College of Engineering, Universiti Tenaga Nasional, Km 7, Jalan Kajang-Puchong, 43009, Kajang, Selangor Malaysia 
Table 2: Thermodynamic properties expressed as a function of crank angle and temperature ${ }^{[1]}$

Specific internal energy

$\frac{d u_{b}}{d \theta}=\left(c_{P b}-\frac{P v_{b}}{T_{b}} \frac{\partial \ln v_{b}}{\partial \ln T_{b}}\right) \frac{d T_{b}}{d \theta}-v_{b}\left(\frac{\partial \ln v_{b}}{\partial \ln T_{b}}+\frac{\partial \ln v_{b}}{\partial \ln P}\right) \frac{d P}{d \theta}$

$\frac{d u_{u}}{d \theta}=\left(c_{P u}-\frac{P v_{u}}{T_{u}} \frac{\partial \ln v_{u}}{\partial \ln T_{u}}\right) \frac{d T_{u}}{d \theta}-v_{u}\left(\frac{\partial \ln v_{u}}{\partial \ln T_{u}}+\frac{\partial \ln v_{u}}{\partial \ln P}\right) \frac{d P}{d \theta}$

Specific volume

$\frac{d v_{b}}{d \theta}=\frac{v_{b}}{T_{b}} \frac{\partial \ln v_{b}}{\partial \ln T_{b}} \frac{d T_{b}}{d \theta}+\frac{v_{b}}{P} \frac{\partial \ln v_{b}}{\partial \ln P} \frac{d P}{d \theta}$

$\frac{d v_{u}}{d \theta}=\frac{v_{u}}{T_{u}} \frac{\partial \ln v_{u}}{\partial \ln T_{u}} \frac{d T_{u}}{d \theta}+\frac{v_{u}}{P} \frac{\partial \ln v_{u}}{\partial \ln P} \frac{d P}{d \theta}$

Specific entropy $\frac{d s_{u}}{d \theta}=\left(\frac{C_{p_{u}}}{T_{u}}\right) \frac{d T_{u}}{d \theta}-\frac{v_{u}}{T_{u}} \frac{\partial \ln v_{u}}{\partial \ln T_{u}} \frac{d P}{d \theta}$

Specific enthalpy

$\left(\frac{\partial h}{\partial T}\right)_{p}=C_{p}$

$\frac{C_{p}}{R}=a_{1}+a_{2} T+a_{3} T^{2}+a_{4} T^{3}+a_{5} T^{4}$

The specific heat change indicates the enthalpy change with respect to temperature and specific heat is obtained from curve fitted polynomial equation. Table 2 shows the thermodynamic properties expressed as a function of crank angle, pressure and temperature.

Solution procedure: Recalling equation (2) and combining all the derivatives will enable the pressure and temperature to be expressed as a function of crank angle, pressure, unburned gas temperature and burned gas temperature.

$\frac{d P}{d \theta}, \frac{d T_{b}}{d \theta}, \frac{d T_{u}}{d \theta}=f_{1}\left(\theta, P, T_{b}, T_{u}\right)$

Solving the above equations with appropriate input data enable determination of the indicated work, enthalpy and heat loss throughout the system since indicated work, enthalpy and heat loss can be expressed as a function of pressure and temperature as well.

$\frac{d W}{d \theta}=f_{4}(\theta, P)$

$\frac{d Q_{l}}{d \theta}=f_{5}\left(\theta, P, T_{b}, T_{u}\right)$

$\frac{d H_{l}}{d \theta}=f_{6}\left(\theta, P, T_{b}, T_{u}\right)$

The derivatives of the equation (3-6) with the combination of the thermodynamic properties equations are:

$\frac{d P}{d \theta}=\frac{A+B+C}{D+E}$ $\frac{d T_{b}}{d \theta}=\frac{-h\left(\frac{\pi b^{2}}{2}+\frac{4 V}{b}\right) x^{1 / 2}\left(T_{u}-T_{w}\right)}{\omega m c_{P_{b}} x}+$
$\frac{v_{b}}{c_{P_{b}}} \frac{\partial \ln v_{b}}{\partial \ln T_{b}}\left(\frac{A+B+C}{D+E}\right)+\frac{h_{u}-h_{b}}{x c_{P_{b}}}\left[\frac{d x}{d \theta}-\left(x-x^{2}\right) \frac{C}{\omega}\right]$

$\frac{d T_{u}}{d \theta}=\frac{-h\left(\frac{\pi b^{2}}{2}+\frac{4 V}{b}\right)\left(1-x^{1 / 2}\right)\left(T_{u}-T_{w}\right)}{\omega m c_{P_{u}}(1-x)}$

$+\frac{v_{u}}{c_{P_{u}}} \frac{\partial \ln v_{u}}{\partial \ln T_{u}}\left(\frac{A+B+C}{D+E}\right)$

$\frac{d W}{d \theta}=P \frac{d V}{d \theta}$

$\frac{d Q_{l}}{d \theta}=\frac{h}{\omega}\left(\frac{\pi b^{2}}{2}+\frac{4 V}{b}\right)\left[x^{1 / 2}\left(T_{b}-T_{u}\right)+\left(1-x^{1 / 2}\right)\left(T_{u}-T_{w}\right)\right]$

$\frac{d H_{l}}{d \theta}=\frac{C m}{\omega}\left[\left(1-x^{2}\right) h_{u}+x^{2} h_{b}\right]$

Where:

$A=\frac{1}{m}\left(\frac{d V}{d \theta}+\frac{V C}{\omega}\right)$

$B=h \frac{\left(\frac{\pi b^{2}}{2}+\frac{4 V}{b}\right)}{\omega m}\left[\begin{array}{l}\frac{v_{b}}{c_{P_{b}}} \frac{\partial \ln v_{b}}{\partial \ln T_{b}} x^{1 / 2} \frac{T_{b}-T_{w}}{T_{b}}+ \\ \frac{v_{u}}{c_{P_{u}}} \frac{\partial \ln v_{u}}{\partial \ln T_{u}}\left(1-x^{1 / 2}\right) \frac{T_{u}-T_{w}}{T_{u}}\end{array}\right]$

$C=-\left(v_{b}-v_{u}\right) \frac{d x}{d \theta}-v_{b} \frac{\partial \ln v_{b}}{\partial \ln T_{b}} \frac{h_{u}-h_{b}}{c_{P_{b}} T_{b}}\left[\frac{d x}{d \theta}-\frac{\left(x-x^{2}\right) C}{\omega}\right]$

$D=x\left[\frac{v_{b}{ }^{2}}{c_{P_{b}} T_{b}}\left(\frac{\partial \ln v_{b}}{\partial \ln T_{b}}\right)^{2}+\frac{v_{b}}{P} \frac{\partial \ln v_{b}}{\partial \ln P}\right]$

$E=(1-x)\left[\frac{v_{u}{ }^{2}}{c_{P_{u}} T_{u}}\left(\frac{\partial \ln v_{u}}{\partial \ln T_{u}}\right)^{2}+\frac{v_{u}}{P} \frac{\partial \ln v_{u}}{\partial \ln P}\right]$

Equilibrium combustion products: In order to track $\mathrm{NO}_{x}$ formation, the equilibrium state of $\mathrm{O}_{2}$ and $\mathrm{N}_{2}$ need to be determined. Therefore, from the Olikara and Borman method, the chemical equilibrium of the combustion products can be determined by considering the dissociation effects of the $\mathrm{O}, \mathrm{H}, \mathrm{OH}, \mathrm{NO}$ species.

The general chemical formula is ${ }^{[1,2]}$ :

$\varepsilon \phi C_{\alpha} H_{\beta} O_{\gamma} N_{\delta}+\left(0.21 O_{2}+0.79 N_{2}\right) \rightarrow v_{1} C O_{2}$

$+v_{2} \mathrm{H}_{2} \mathrm{O}+v_{3} \mathrm{~N}_{2}+v_{4} \mathrm{O}_{2}+v_{5} \mathrm{CO}+$ 


$$
v_{6} \mathrm{H}_{2}+v_{7} \mathrm{H}+v_{8} \mathrm{O}+v_{9} \mathrm{OH}+v_{10} \mathrm{NO}
$$

However, in this case the $C$ atom does not exist since the hydrogen fuel was being used. Thus, the chemical formula becomes:

$$
\begin{aligned}
& \varepsilon \phi \mathrm{H}_{\beta} \mathrm{O}_{\gamma} \mathrm{N}_{\delta}+\left(0.21 \mathrm{O}_{2}+0.79 \mathrm{~N}_{2}\right) \rightarrow y_{1} \mathrm{H}_{2} \mathrm{O} \\
& +y_{2} \mathrm{~N}_{2}+y_{3} \mathrm{O}_{2}+y_{4} \mathrm{H}_{2}+ \\
& y_{5} \mathrm{H}+y_{6} \mathrm{O}+y_{7} \mathrm{OH}+y_{8} \mathrm{NO}
\end{aligned}
$$

Since atoms are conserved, three equations for the unknowns are obtained as below:

$$
\begin{aligned}
& \varepsilon \phi \beta=\left(2 y_{1}+2 y_{4}+y_{5}+y_{7}\right) N \\
& \varepsilon \phi \gamma+0.42=\left(y_{1}+2 y_{3}+y_{6}+y_{7}+y_{8}\right) N \\
& \varepsilon \phi \delta+1.58=\left(2 y_{2}+y_{8}\right) N
\end{aligned}
$$

where, $N$ is the total number of moles and $y$ is the mole fraction. Thus, the total number of mole fraction must be equal to one and this gives:

$$
\sum_{i=1}^{10} y_{i}-1=0
$$

The dissociation effect of $\mathrm{O}, \mathrm{H}, \mathrm{OH}, \mathrm{NO}$ species gives the following five equations as listed in Table $3^{[1]}$.

Experimental data for $K_{1}, K_{2}, K_{3}, K_{4} \& K_{5}$ in the form of curve fits were then put into equations inside Table 3 for calculations ${ }^{[1]}$. Through algebraic manipulations, the nine equations can be reduced into four equations with four unknowns. The equations are nonlinear and solved by using the Newton method. The general form of Newton method for nonlinear systems is:

$G(x)=x-A(x)^{-1} F(x)$

Table 3: Equations to express the dissociation effect for distinct gases

$$
\begin{array}{ll}
\hline \frac{1}{2} H_{2} \Leftrightarrow H & K_{1}=\frac{y_{5} P^{1 / 2}}{y_{4}{ }^{1 / 2}} \\
\frac{1}{2} O_{2} \Leftrightarrow O & K_{2}=\frac{y_{6} P^{1 / 2}}{y_{3}{ }^{1 / 2}} \\
\frac{1}{2} H_{2}+\frac{1}{2} O_{2} \Leftrightarrow O H & K_{3}=\frac{y_{7}}{y_{3}{ }^{1 / 2} y_{4}{ }^{1 / 2}} \\
\frac{1}{2} O_{2}+\frac{1}{2} N_{2} \Leftrightarrow N O & K_{4}=\frac{y_{8}}{y_{3}^{1 / 2} y_{2}{ }^{1 / 2}} \\
H_{2}+\frac{1}{2} O_{2} \Leftrightarrow H_{2} O & K_{5}=\frac{y_{1}}{y_{3}{ }^{1 / 2} y_{4} P^{1 / 2}} \\
\hline
\end{array}
$$

where, $A(x)$ is the Jacobian matrix and $F(x)$ is the functions and the functional iteration procedure evolves from:

$x^{(k)}=G\left(x^{(k-1)}\right)=x^{(k-1)}-J\left(x^{(k-1)}\right)^{-1} F\left(x^{(k-1)}\right)$

The solution is generally expected to give quadratic convergence, provided that a sufficiently accurate initial guess and the inverse of the Jacobian matrix exist. Thermodynamic properties such as enthalpy, internal energy, entropy can be determined as the temperature and pressure change based on the concentrations of the 8 constituents. A modified version of the Olikara and Borman method for hydrogen fuel is presented on the Fig. 1 for investigation of distinct gas mole fraction as the temperature change. In order to validate the subroutine, the mole fraction change with respect to temperature of the Octane fuel based on the general chemical formula is compared to the diagram provided $^{[1]}$. Good agreement was obtained.

The $N O_{x}$ model: The $N O_{x}$ is the general term for the combination of $\mathrm{NO}$ and $\mathrm{NO}_{2}$. In high temperature combustion e.g. hydrogen gas with oxygen, the $N O_{x}$ formation is the maibringern since $N O_{x}$ can bring the adverse effect to the environment. The mechanism of $N O$ formation is expressed as the following:

$\mathrm{O}+\mathrm{N}_{2}=\mathrm{NO}+\mathrm{N}$
$\mathrm{N}+\mathrm{O}_{2}=\mathrm{NO}+\mathrm{O}$
$\mathrm{N}+\mathrm{OH}=\mathrm{NO}+\mathrm{H}$

The rate of $N O$ formation has strong temperature dependence and the reaction rate was expressed as:

$\frac{d[N O]}{d t}=k_{1}^{+}[O]\left[N_{2}\right]+k_{2}^{+}[N]\left[O_{2}\right]+k_{3}^{+}[N][O H]$
$-k_{1}^{-}[N O][N]-k_{2}{ }^{-}[N O][O]-k_{3}^{-}[N O][H]$

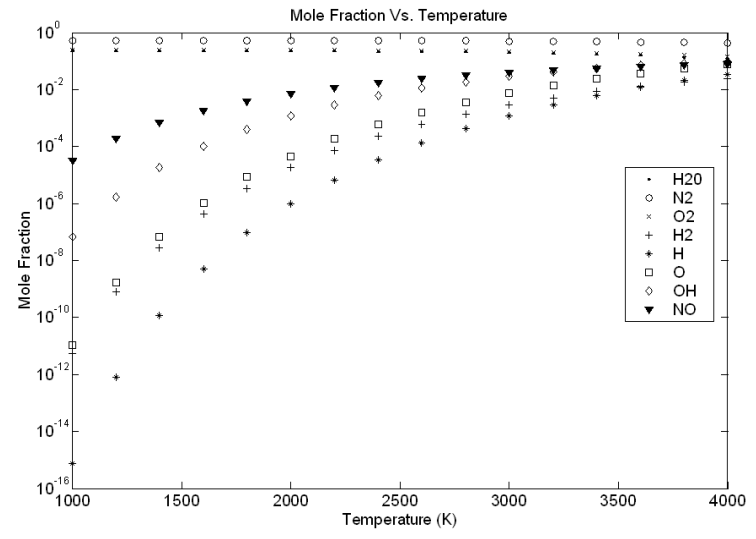

Fig. 1: Mole fraction vs. temperature data generated by the program@P=50atm \& $\phi=0.8$ 


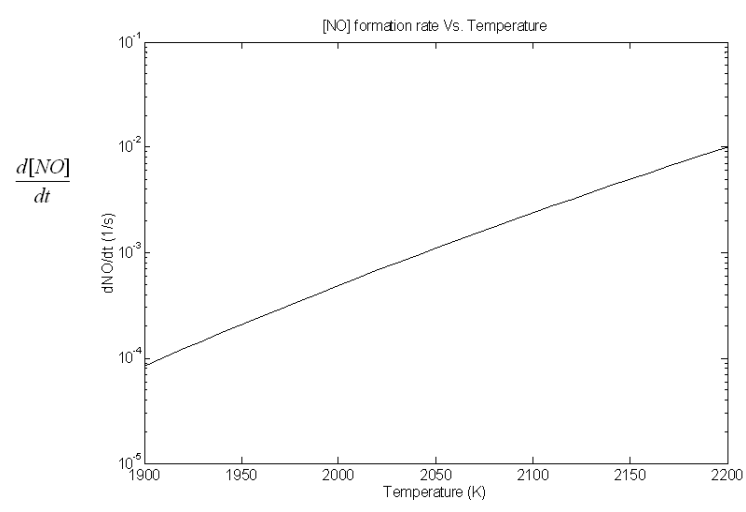

Fig. 2: The $[\mathrm{NO}]$ formation rate Vs. Temperature of $\mathrm{H}_{2}$ fuel

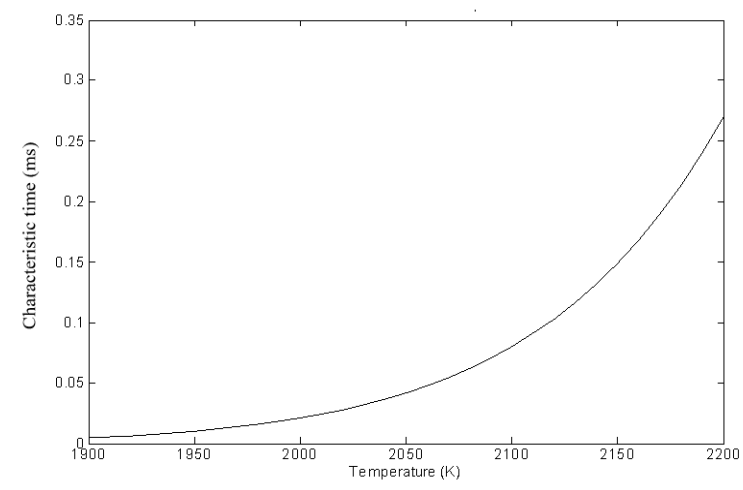

Fig. 3: The characteristic time vs. Temperature

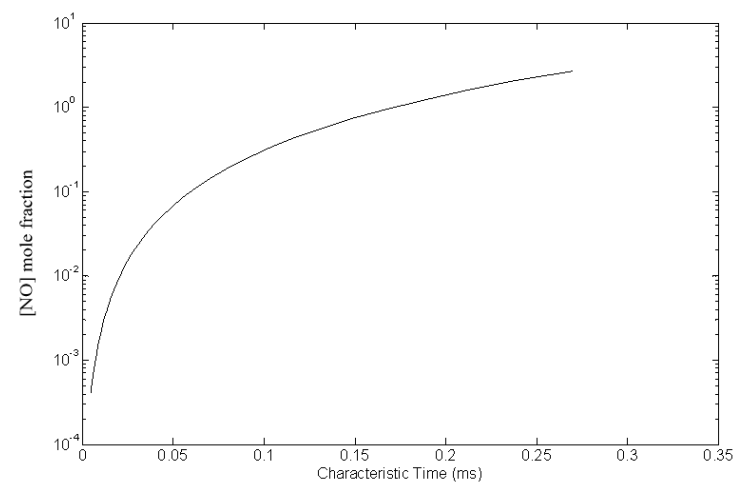

Fig. 4: The $[N O]$ mole fraction vs. Characteristic time

Likewise for the $N$ formation:

$$
\begin{aligned}
& \frac{d[N]}{d t}=k_{1}^{+}[O]\left[N_{2}\right]-k_{2}^{+}[N]\left[O_{2}\right]-k_{3}^{+}[N][O H] \\
& -k_{1}^{-}[N O][N]+k_{2}^{-}[N O][O]+k_{3}^{-}[N O][H]
\end{aligned}
$$

The $[[N]]$ represents the mole concentration and $k_{i}$ was the rate constant ${ }^{[3]}$. In most engine combustion cases, the steady state approximation for $N$ formation $\left(\frac{d N}{d t}=0\right)$ was considered to eliminate $[N]$ since the concentration of $[N]$ is approximately zero. Thus, equation (27) becomes:

$$
\frac{d N O}{d t}=2 k_{1}^{+}[O]\left[N_{2}\right] \frac{1-[N O]^{2} /\left(K\left[O_{2}\right]\left[N_{2}\right]\right)}{1+k_{1}^{-}[N O] /\left(k_{2}^{+}\left[O_{2}\right]+k_{3}^{+}[O H]\right)}
$$

From the assumption ${ }^{[3]}$, the post flame gases is much of concern in all in-cylinder combustion as the post flame gases always dominates the flame front gases, the concentrations of $\mathrm{O}, \mathrm{O}_{2}, \mathrm{OH}, \mathrm{H}$ and $\mathrm{N}_{2}$ was assumed by their equilibrium values at local pressure and temperature. Thus, equation (28) becomes:

$\frac{d[N O]}{d t}=\frac{6 x 10^{16}}{T^{1 / 2}} \exp \left(\frac{-69090}{T}\right)\left[O_{2}\right]_{e}^{1 / 2}\left[N_{2}\right]_{e}$

where, $\left[\mathrm{O}_{2}\right]_{e}$ and is the equilibrium state of mole fracproductain from the equilibrium combustion product model. Figure 2 shows the $[\mathrm{NO}]$ formation rate with respect to temperature for $\mathrm{H}_{2}$ fuel.

Equation (29) shows that the $N O$ formation is highly dependent on temperature in the exponential term. However, Error! Bookmark not defined. the concentration will change as the time changes $\left(\frac{d[N O]}{d t}\right)$. Therefore, the characteristic time for the $N O$ formation process is defined as:

$$
\tau_{N O}^{-1}=\frac{1}{[N O]_{e}} \frac{d[N O]}{d t}
$$

and $\tau_{N O}$ is given by:

$$
\tau_{N O}=\frac{8 x 10^{-16} T \exp (58300 / T)}{p^{1 / 2}}
$$

The characteristic time changes as the local temperature changes as shown in Fig. 3, but the pressure remains constant in the case of adiabatic constant pressure combustion, which is applicable for each element of fuel that burns in an engine. Figure 4 shows the variation of the $[\mathrm{NO}]$ mole fraction against characteristic time.

\section{RESULTS}

Effects of equivalence ratio: In order to simulate a realistic case, a Nissan A15 engine specification was used for the simulation study. This engine was applicable in gasoline, LPG and CNG fuel operation. The simulation is to predict the engine modifications required for hydrogen fuel. Table 4 shows the specifications of the engine. 
Table 4: Nissan A15 engine specifications

\begin{tabular}{ll}
\hline \multicolumn{2}{c}{ Specifications } \\
\hline Intermittent output & $46 \mathrm{Hp} @ 3,600 \mathrm{rpm}$ \\
Continuous output & $39 \mathrm{Hp} @ 3,600 \mathrm{rpm}$ \\
Peak torque & $11 \mathrm{~kg} . \mathrm{m} @ 2,200 \mathrm{rpm}$ \\
Minimum fuel consumption & $225 \mathrm{~g} / \mathrm{Hp} . \mathrm{hr} @ 3,200 \mathrm{rpm}$ \\
Cylinder arrangement & 4 in line \\
Combustion chamber & Wedge shape \\
Bore x Stroke & $76 \times 82 \mathrm{~mm}$ \\
Total piston displacement & $1,487 \mathrm{cc}$ \\
Compression ratio & $9: 1$ \\
\hline
\end{tabular}

IMEP \& Thermal efficiency. Vs. Equivalence ratio

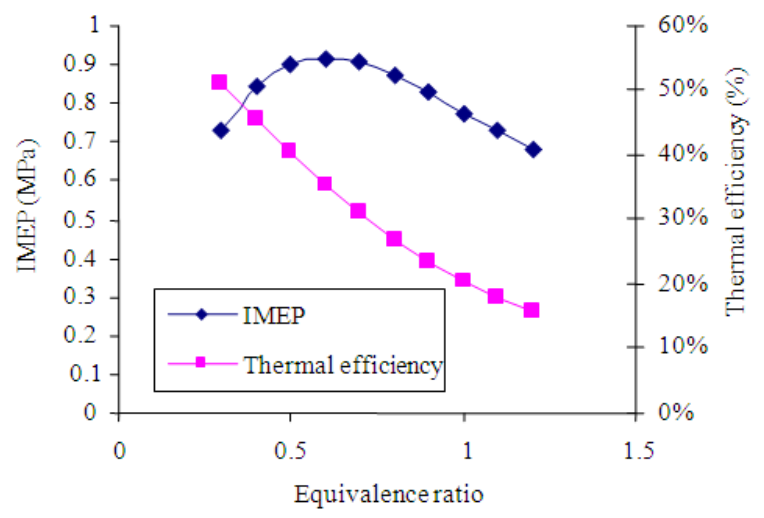

Fig. 5: IMEP and indicated thermal efficiency vs. equivalence ratio@3,600rpm

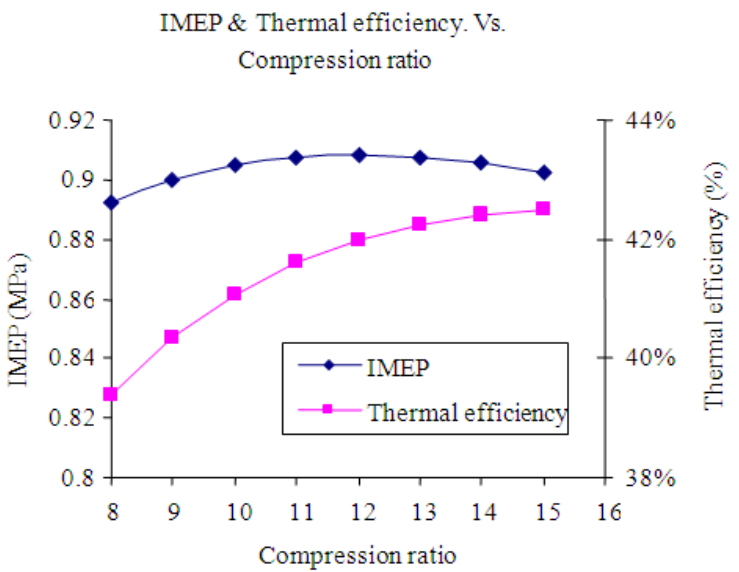

Fig. 6: IMEP and indicated thermal efficiency vs. Compression ratio @ $3,600 \mathrm{rpm} \& \phi=0.5$

Figure 5 shows the result of IMEP and indicated thermal efficiency for different equivalence ratios. The simulation test was run at 3,600 RPM, which is the maximum output of gasoline fuel. This simulation helps to predict the best equivalence ratio to operate a hydrogen-fuelled engine. The indicated mean effective pressure rises as the equivalence ratio increases, however it starts to drop from 0.6. Thermal efficiency starts to decrease exponentially as the equivalence ratio increases. For complete hydrogen-air combustion or a stoichiometric combustion, the air fuel ratio is 34.3, which means that hydrogen fuel operates better under an ultra-lean condition ${ }^{[4]}$. The thermal efficiency drop indicated the incomplete combustion of hydrogen-air mixture inside the combustion chamber. In this case, a 0.5 value of equivalence ratio was chosen for the following simulation since the equivalence ratio of 0.6 gives a rather low thermal efficiency.

Effects of compression ratio: The engine default compression ratio was 9:1; however this should be changed to suit the hydrogen fuel operation. In order to predict the suitable compression ratio for hydrogen fuel, the simulation test was run at 0.5 equivalence ratio. Figure 6 shows the variation of IMEP and thermal efficiency with the compression ratio.

The results indicate that as the compression ratio increases, the indicated thermal efficiency starts to increase exponentially but IMEP start to drop at compression ratio 12 . Theoretically, the compression ratio has a great effect on the terminal combustion pressure. The increase of compression ratio results in increase of cylinder top pressure as well as cylinder temperature. However, a high temperature and pressure environment may cause knock to happen inside the combustion chamber. Autoignition may occur as the compression ratio increase more than 12 .

Effects of spark timing: Spark timing is a major operating parameter that affects spark ignition engine performance, efficiency and emissions at any given load and speed. If combustion starts too early in the cycle, the work transfer from the piston to the gases at the end of the compression stroke is too large. If the combustion starts too late, the peak cylinder pressure is reduced and the expansion stroke work transfer from the gas to the piston decreases. In order to optimize, the best results from the previous simulation were used and the parameters were used as inputs for the following simulation to predict the optimum spark timing. Figure 7 shows the effect of spark timing on of the IMEP and thermal efficiency.

The results indicate that the best spark timing was at $-15^{\circ}$ BTDC since it gives the best IMEP and indicated thermal efficiency output. Hydrogen has low ignition energy but the autoignition temperature is high compared to gasoline ${ }^{[5]}$. Thus, hydrogen is hard to burn with air in a compression ignition engine. However, in this case the spark plug aids the ignition of the hydrogen-air mixture which solves the major problem $^{[6,7]}$. As mentioned earlier, the ignition delay may cause the peak pressure to reduce which results in IMEP decrease since the work done through the control volume is less ${ }^{[8]}$. 


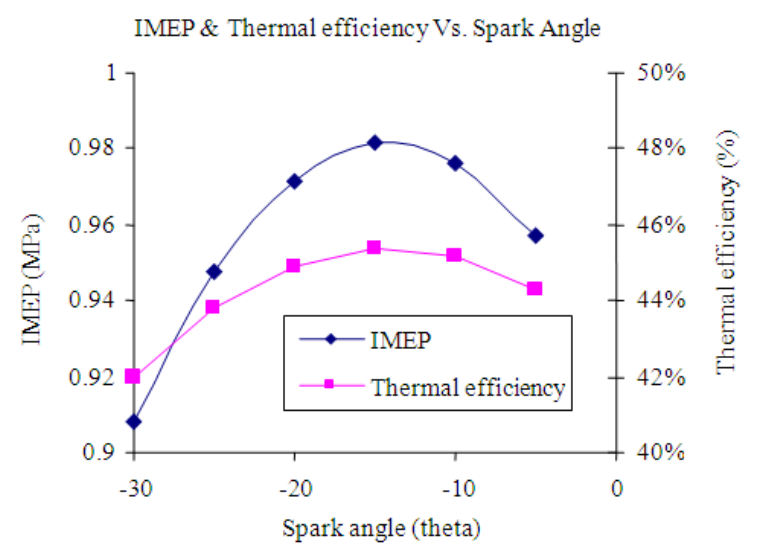

Fig. 7: IMEP \& thermal efficiency vs. Spark angle @ 3, 600rpm, $\phi=0.5 \& \mathrm{CR}=12$

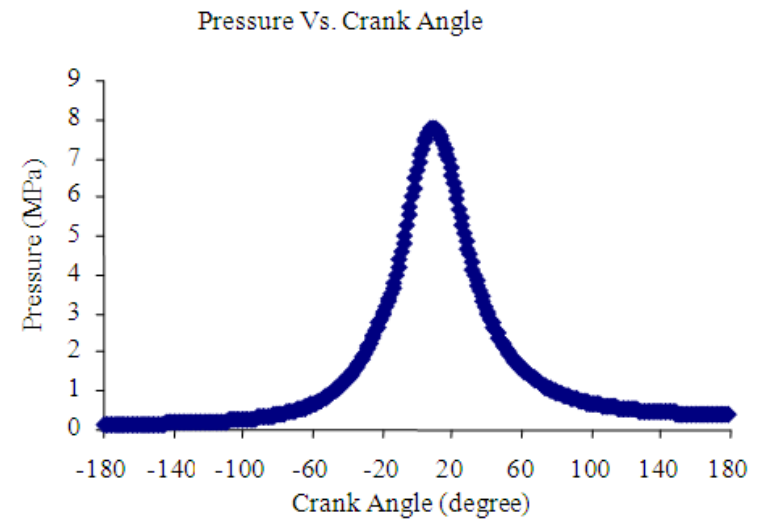

Fig. 8: Pressure vs. Crank angle

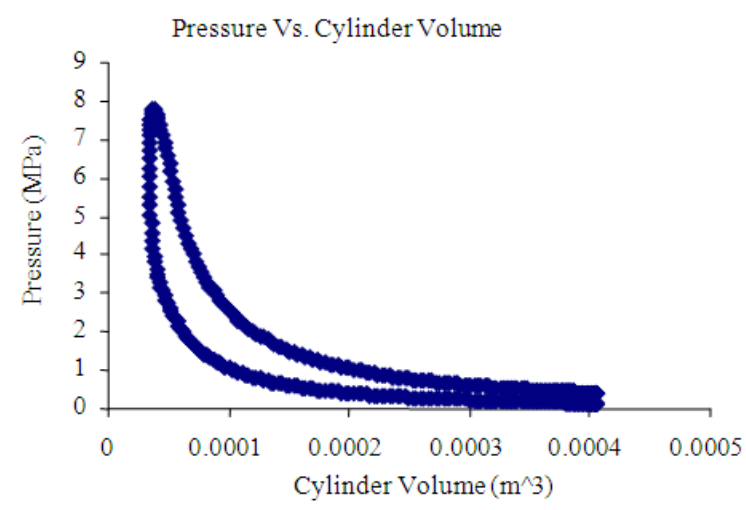

Fig. 9: Pressure vs. Volume

Figures 8 and 9 shows the pressure history of the engine cycle where the maximum output pressure was expected to be $80 \mathrm{MPa}$. Figures 10 and 11 show the temperature and heat flux for both burned and unburned gasses in the engine cycle. The heat flux was actually determined by making use of the temperature history in Figure 10 and applying the Newton's law. The IMEP variation with crank angle is shown in Fig. 12.
Gas Temperature Vs. Crank Angle

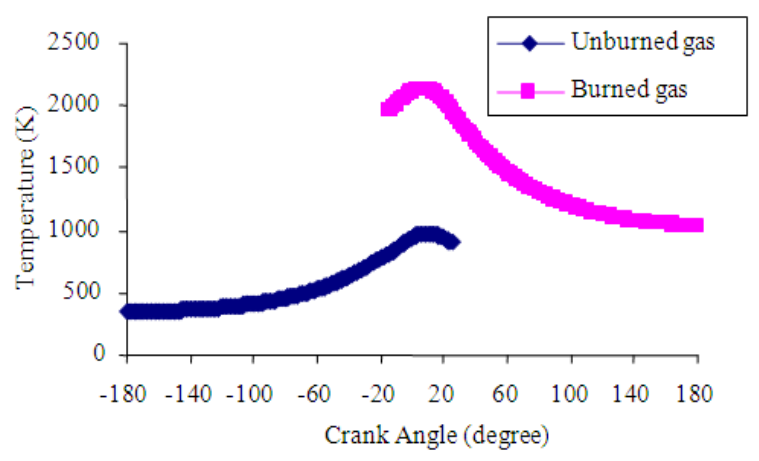

Fig. 10: Temperature vs. Crank angle

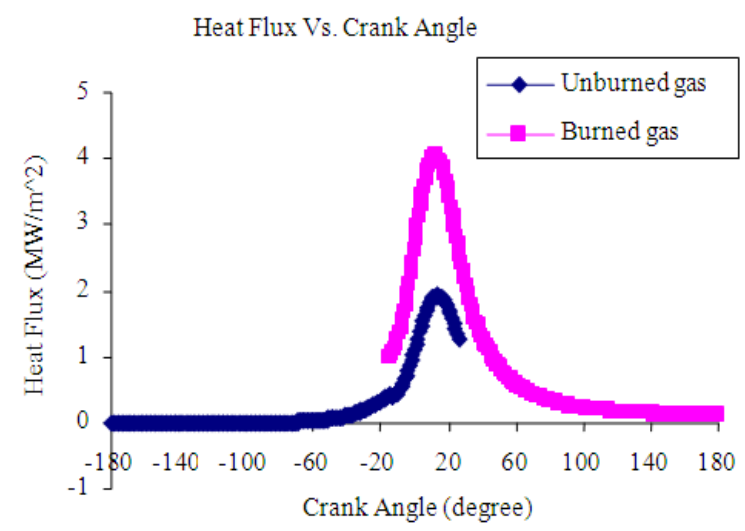

Fig. 11: Heat flux vs. Crank angle

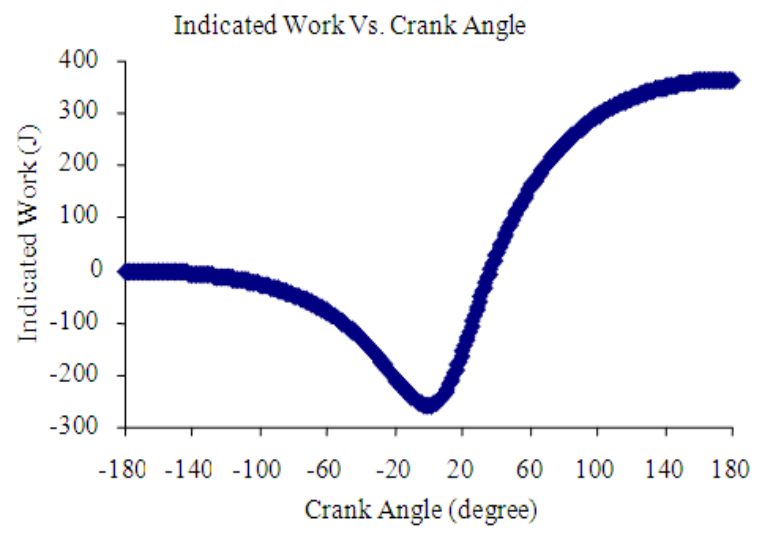

Fig. 12: Indicated work vs. Crank angle

The heat transfer and losses of the engine are shown in Fig. 13 and 14, respectively, where the adiabatic flame temperature is used as the initial temperature of the burned gas at the start of heat release. The temperature is then iteratively adjusted until the burned and unburned enthalpies are equal. Figure 15 shows the graphical user interface of the program. 


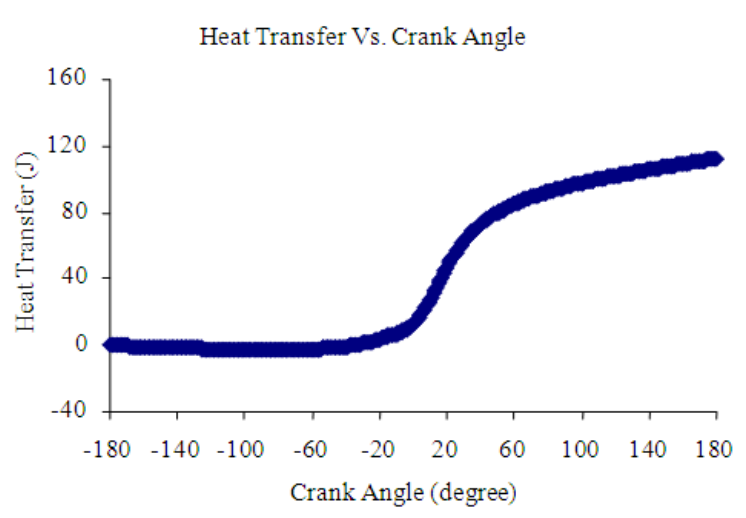

Fig. 13: Heat transfer vs. Crank angle

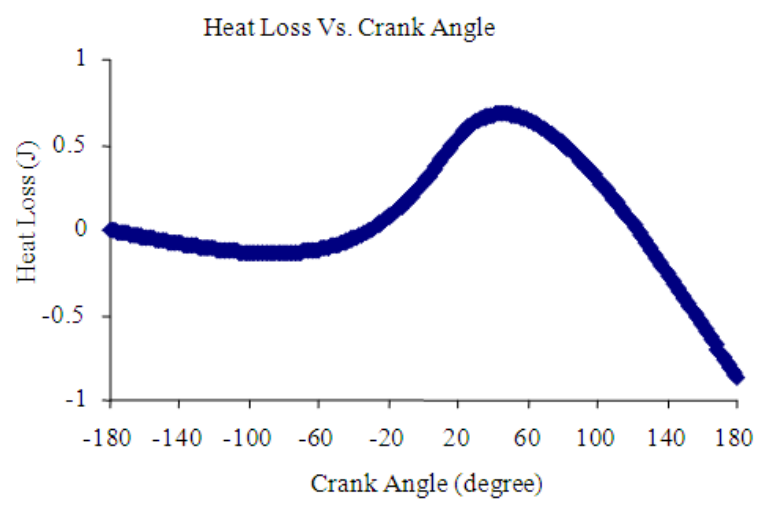

Fig. 14: Heat loss vs. Crank angle

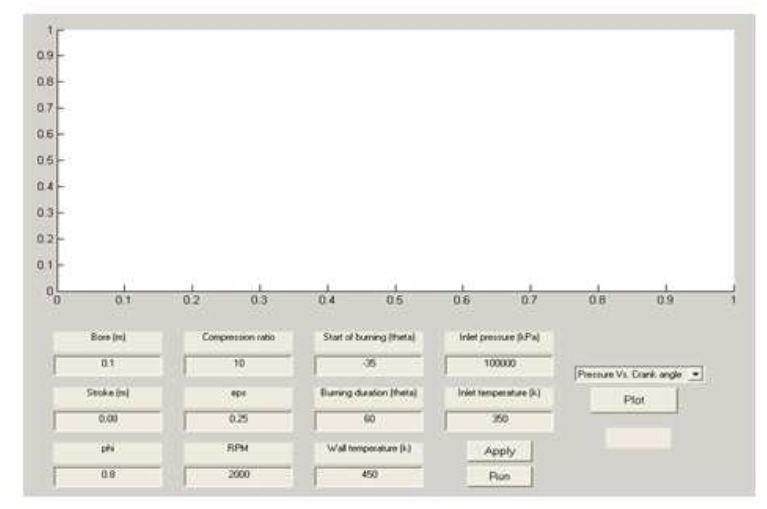

Fig. 15: The graphical user interface (GUI) of the program

\section{CONCLUSION}

The mathematical model used to predict the engine performance of fuel inducted type spark ignition engine is presented. Based on the Olikara and Borman method, a subroutine for the equilibrium combustion product was developed and compared with ${ }^{[1]}$. Good agreement was obtained. A model based on modified Olikara and Borman method for hydrogen fuel calculations was developed and the simulation result agreed well with those reported ${ }^{[1]}$ with no carbon content exist. The $N O_{x}$ model was developed based on the equilibrium combustion products of $\mathrm{O}_{2}$ and $N_{2 e}$ species mole fraction at equilibrium state. The result of $\mathrm{NO}_{x}$ formation rate was comparable with ${ }^{[3]}$.

\section{REFERENCES}

1. Colin, R. Ferguson, 1986. Internal Combustion Engines- Applied Thermo sciences. John Willey and Sons, 1st Edn., 2nd Edn., 2000.

2. Abd Alla, G.H. 2002. Computer simulation of a four stroke spark ignition engine. Energy Conversion \& Management, 43: 1043-1061.

3. John B. Heywood, 2003. Internal Combustion Engine Fundamentals. McGraw-Hill.

4. Das, L.M., Gulati, Rohita and P.K. Gupta, 2000. Performance characteristics of a hydrogen fuelled spark ignition engine using electronically controlled solenoid actuated injection system. Int. J. Hydrogen Energy, 25: 783-93.

5. Das, L.M., 2002. Hydrogen engine, research and development $(R \& D)$ programs in Indian Institute of Technology (IIT), Delhi. Int. J. Hydrogen Energy, 27: 953-965.

6. Maher A.R. Sadiq Al-Baghdadi, 2004. Effect of compression ratio, equivalence ratio and engine speed on the performance and emission characteristics of a spark ignition engine using hydrogen as a fuel. Renewable Energy, pp: 1-16.

7. Jie Ma, Yong Kang Su, Yucheng Zhou and Zhongli Zhang, 2003. Simulation and prediction on the performance of a vehicle's hydrogen engine. Int. J. Hydrogen Energy, 28: 77-83.

8. Arturo De Risi, Raffaele Zecca and Domenico Laforgia, 2000. Optimization of a 4 stroke engine by means of experimental and 1-D numerical analysis. Society of Automotive Engineers, Inc., SAE2000-01-0566. 